\title{
Treatment of Squamous Cell Carcinoma of the Esophagus Synchronously Associated with Head and Neck Cancer
}

\author{
MASARU MORITA ${ }^{1}$, AKINORI EGASHIRA ${ }^{1}$, YU NAKAJI $^{1}$, MASAKI KAGAWA $^{1}$, \\ MASAHIKO SUGIYAMA ${ }^{1}$, DAISUKE YOSHIDA ${ }^{1}$, MITSUHIKO OTA ${ }^{1}$, MASAHIKO IKEBE ${ }^{1}$, \\ MUNEYUKI MASUDA ${ }^{2}$, YOJIRO INOUE ${ }^{3}$, NAONOBU KUNITAKE $^{4}$ and YASUSHI TOH ${ }^{1}$ \\ Departments of ${ }^{1}$ Gastroenterological Surgery, ${ }^{2}$ Head and Neck Surgery, \\ ${ }^{3}$ Plastic Surgery and ${ }^{4}$ Radiology, National Kyushu Cancer Center, Fukuoka, Japan
}

\begin{abstract}
Background/Aim: The aim of this study was to clarify the treatment strategy for synchronous squamous cell carcinoma of the esophagus (ESCC) and head and neck cancer (HNC). Patients and Methods: Treatment outcomes of 91 patients with synchronous ESCC and HNC were evaluated. Thirty-eight patients received simultaneous definitive chemoradiotherapy (CRT) and 15 patients underwent simultaneous resection. Results: Among the patients who received simultaneous $C R T$, adverse events (grade 3-5) were recognized in 14 patients (40\%), including one case of death due to aspiration pneumonia. Complete response was observed in 22 patients with ESCC (58\%) and 19 patients with HNC (50\%). The five-year survival rate was $44 \%$. There were no in-hospital deaths after simultaneous resection; however, postoperative complications were recognized in 4 patients. The five-year OS was 70\%. Conclusion: The treatment of synchronous ESCC and HNC must be decided by adopting a strategy that is appropriate for each case. Both simultaneous CRT and simultaneous resection are feasible and effective treatment options.
\end{abstract}

The multifocal development of squamous cell carcinoma (SCC) is frequently observed in the upper aerodigestive tract (UADT) including the head and neck region and the esophagus. The association of these cancers is observed both synchronously and metachronously (1). These cancers are

This article is freely accessible online.

Correspondence to: Prof. Masaru Morita, Department of Gastroenterological Surgery, National Kyushu Cancer Center, 3-11 Notame, Minami-ku, Fukuoka 811-1395, Japan. Tel: +81 925413231, Fax: +81 925428503, e-mail: masarum@nk-cc.go.jp

Key Words: Esophageal cancer, head and neck cancer, synchronous double cancer. highly aggressive and until relatively recently were usually associated with a dismal prognosis. Environmental factors such as cigarette smoking and alcohol drinking are closely related to the development of SCC of the UADT. Furthermore, we have reported that both heavy smoking and heavy drinking have synergistic effects on multi-centric carcinogenesis of the UADT $(1,2)$.

Regarding the treatment strategy, surgical resection has been the gold standard of treatment for localized UADT cancer. However, this surgery is extremely invasive and is also associated with high rates of mortality and morbidity, especially in patients with esophageal cancer and pharyngeal cancer $(3,4)$. Patients with synchronous squamous cell carcinoma of the esophagus (ESCC) and head and neck cancer (HNC) often require for extremely complex and invasive surgical procedures in order to resect both lesions (5-7). The surgical procedures for synchronous double cancer therefore represent an important clinical problem.

On the other hand, squamous cell carcinoma of the UADT is relatively sensitive to radiation and anticancer drugs such as 5-fluorouracil, cisplatin and paclitaxel (8-10). Definitive chemoradiotherapy is frequently indicated for ESCC while invasive esophagectomy is normally avoided (11). For patients with HNC, the preservation of the vocal function can be achieved if $\mathrm{HNC}$ is cured after definitive chemoradiotherapy (CRT). Definitive CRT for synchronous ESCC and HNC is controversial due to the larger radiation field and associated toxicity (12). In our institute, simultaneous definitive CRT has been applied in the treatment of synchronous ESCC and HNC $(13,14)$. Another problem is that salvage treatment, which is frequently troublesome, may be indicated in cases with either residual or recurrent cancer after definitive CRT $(4,11)$.

In this study, we reviewed the clinical characteristics and treatment outcomes in 91 patients with synchronous ESCC and $\mathrm{HNC}$, and paid special attention to simultaneous surgical resection and simultaneous CRT for both cancers. 


\section{Patients and Methods}

Nine hundred forty-one Japanese patients with ESCC were treated from April 2003 to March 2015 in the Department of Gastroenterological Surgery at National Kyushu Cancer Center in Japan. Among these patients, 91 patients (9.7\%) had synchronous HNC, which was histologically proven to be squamous cell carcinoma. Synchronous double cancers were defined as cancers which were diagnosed within 1 year. The study population included 86 men and 64 women (mean age $=63.7$ years).

This work was approved by the Institutional Review Board (No 2016-77) of our institution. The clinicopathological factors of both ESCC and HNC were evaluated according to the TNM classification of malignant tumors (7th edition) by UICC (15). The clinical characteristics of both cancers were evaluated and the treatment methods and outcomes were evaluated. Special attention was paid to 38 patients who underwent simultaneous definitive chemoradiotherapy as well as 15 patients who underwent simultaneous surgical resection for ESCC and HC.

The treatment strategies were mainly decided based on the tumor stages of the cancers by both esophageal surgeons and head and neck surgeons. The presence of more advanced tumors, which were thought to more strongly influence the prognosis, are important to consider when deciding the treatment strategy. For mucosal ESCC, either endoscopic resection or definitive CRT was generally indicated. If simultaneous surgical resection is indicated, a one-stage operation for ESCC and HNSCC was generally selected, while a two-stage operation consisting of initial resection followed by reconstruction was indicated for high-risk patients. For HNC, the indications for surgical resection were carefully decided, and other therapeutic methods, such as CRT, initially tended to be selected in order to preserve the vocal and swallowing functions.

Regarding simultaneous definitive CRT for both cancers, the daily fractional radiation dose was 1.2-2 Gy (median, $1.6 \mathrm{~Gy}$ ), administered 5 days per week. The total radiation dose was $60 \mathrm{~Gy}$ for ESCC and 70 Gy for HNSCC. The initial radiotherapy field included the head and neck, and mediastinal region. Chemotherapy was performed concurrently with radiotherapy. Chemotherapy consisted of cisplatin/5-FU or platinum-based monotherapy (cisplatin alone or carboplatin alone). The initial treatment response was defined as follows (13): a complete response was defined as the disappearance of the tumor mass on endoscopy, CT, MRI, and/or PET. A partial response was defined as $>30 \%$ regression based on a one-dimensional measurement by endoscopy, CT, or MRI, and no response was defined as $30 \%$ regression or $20 \%$ progression. Acute and late toxicities were graded using the National Cancer Institute Common Terminology Criteria for Adverse Events (CTCAE) version 3.0.

Patients were followed up at a minimum of 1-month intervals during the first year, 3-month intervals until the fifth year, and thereafter on an annual basis. Recurrence was confirmed by a clinical examination, including computed tomography (CT), ultrasonography, endoscopy, [18F]-fluorodeoxyglucose-positron emission tomography CT (FDG-PET CT). Patients visited the outpatient clinic and their tumor marker levels were measured every month for 2 years after surgery and every 3 months, from 3 years until 5 years after surgery. CT scanning and ultrasonography from the neck to the upper abdomen were performed at least twice a year for 3 years after surgery and then once each year from 4 years until 5 years after surgery. Chest roentgenography and endoscopy were
Table I. Clinical background of patients with synchronous double cancers of esophagus and head and neck.

\begin{tabular}{|c|c|c|c|}
\hline \multirow[t]{2}{*}{ Clinical factors } & \multirow[b]{2}{*}{$\begin{array}{l}\text { Total } \\
\mathrm{n}=91\end{array}$} & \multicolumn{2}{|c|}{ Performed therapy } \\
\hline & & $\begin{array}{c}\text { Simultaneous } \\
\text { chemo- } \\
\text { radiotherapy } \\
n=38\end{array}$ & $\begin{array}{c}\text { Simultaneous } \\
\text { resections } \\
\mathrm{n}=15\end{array}$ \\
\hline Age & $68.9 \pm 7.3$ & $64.7 \pm 6.8$ & $61.4 \pm 8.6$ \\
\hline \multicolumn{4}{|c|}{ Gender: male/female } \\
\hline Male & 86 & 36 & 14 \\
\hline Female & 5 & 2 & 1 \\
\hline \multicolumn{4}{|c|}{ Esophageal cancer } \\
\hline \multicolumn{4}{|c|}{ Location of the main tumor } \\
\hline Cervical & 7 & 4 & 2 \\
\hline Upper thoracic & 18 & 3 & 3 \\
\hline Mid-thoracic & 45 & 25 & 5 \\
\hline Lower thoracic & 19 & 5 & 5 \\
\hline Abdominal & 2 & 1 & 0 \\
\hline \multicolumn{4}{|l|}{ TNM stage } \\
\hline I & 64 & 27 & 13 \\
\hline II & 7 & 3 & 1 \\
\hline III & 15 & 6 & 2 \\
\hline IV & 5 & 2 & 0 \\
\hline \multicolumn{4}{|c|}{ Head and neck cancer $*$} \\
\hline \multicolumn{4}{|c|}{ Organ of the tumor } \\
\hline Oral & 16 & 1 & 2 \\
\hline Pharynx & 66 & 32 & 10 \\
\hline Larynx & 14 & 8 & 3 \\
\hline \multicolumn{4}{|l|}{ TNM stage } \\
\hline I & 23 & 9 & 2 \\
\hline II & 21 & 12 & 1 \\
\hline III & 11 & 5 & 4 \\
\hline IV & 36 & 12 & 8 \\
\hline
\end{tabular}

*Including 5 patients with multiple head and neck cancer (three patients received simultaneous CRT).

performed annually to detect anastomotic recurrence as well as second primary cancers, particularly in the head and neck (16).

\section{Results}

The clinical characteristics and therapies performed for synchronous double cancer. Table I shows the clinical background of the patients with synchronous ESCC and HNC. Approximately half of the ESCs were located in the mid-esophagus, while pharyngeal cancer is the most frequently recognized HNC. Multiple esophageal cancers were recognized in 23 patients $(25 \%)$, while synchronous multiple HNCs were recognized in 5 patients (5\%). Early cancers were more frequently recognized in ESCCs than in HNCs. Sixty-four main (70\%) ESCC lesions were diagnosed as TNM stage I, and $53(83 \%)$ of these were detected by endoscopic screening of the previously detected HNC. On 


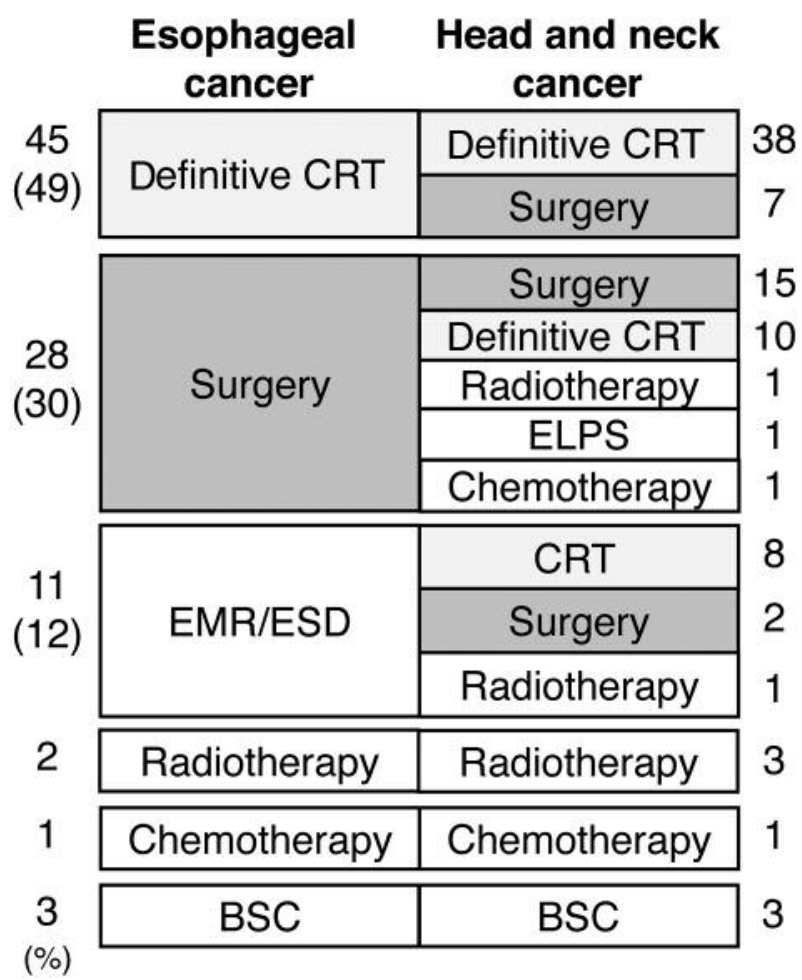

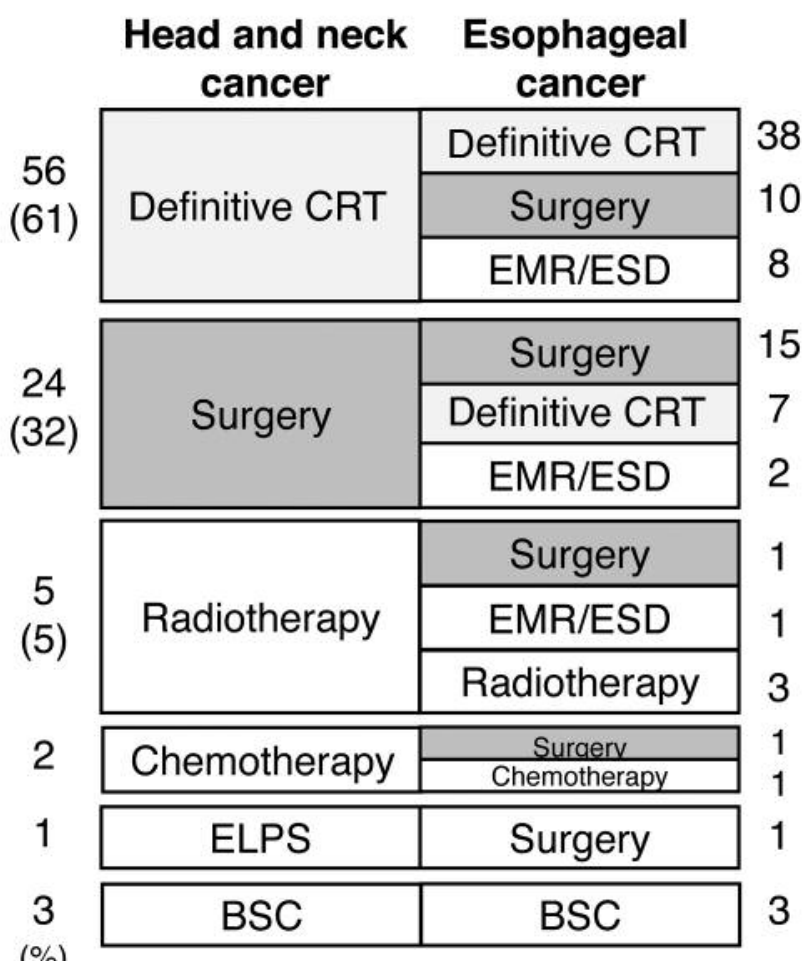

$(\%)$

Figure 1. The main treatments for squamous cell carcinoma of the esophagus and head and neck cancer.

the other hand, 68 of $91 \mathrm{HNC}$ lesions $(75 \%)$ were classified as stage II-IV.

Figure 1 shows the main treatments for ESCC and HNC. Definitive CRT was the most frequently performed therapy. It was performed as the main treatment for 45 patients with ESCC and 56 patients with HNC. Simultaneous definitive CRT for both cancers was performed in 38 patients. Surgical resection was performed in 28 patients with ESCC and 24 patients with HNC. Simultaneous surgical resection was performed in 15 patients. Endoscopic resection was performed in patients with superficial ESCC. Regarding the overall survival of the total of 91 patients, the 3 and 5-year survival rates were $55 \%$ and $44 \%$, respectively (Figure 2A).

Simultaneous definitive CRT. Among the 38 patients who received simultaneous definitive CRT, 27 patients had TNM stage I ESCC, while only 9 patients had Stage I HNC (Table I). Advanced HNC (TNM stage II-IV) associated with stage I ESCC was the most common combination and was recognized in 21 patients. Definitive radiotherapy was completed in 36 patients (95\%). Grade 3-5 adverse events were recognized in 15 patients $(40 \%)$. One patient deceased due to aspiration pneumonia. The most common adverse event was neutropenia, which developed in 8 patients, including febrile neutropenia in 2 patients. Mucositis was observed in 4 patients, while hyponatremia, and hemorrhage from the tumor were recognized in one patient each. Table II shows the therapeutic effect of simultaneous definitive CRT. With regard to the response rates, $79 \%$ of the patients showed a PR and $89 \%$ showed a CR; the CR rates for ESCC and HNC were $58 \%$ and $50 \%$, respectively. All nine stage I HNC lesions showed a $\mathrm{CR}$ after treatment, while the $\mathrm{CR}$ rate was for stage I ESCC was $67 \%$. Table III shows the incidence of recurrence after simultaneous definitive CRT. Recurrence was recognized in 4 of the 22 patients with ESCC who showed a CR after definitive CRT. Before treatment, all of these lesions were initially stage I ESCC. Three patients underwent radiotherapy for recurrent tumors; however, these patients deceased from ESCC. One patient who underwent endoscopic resection for local recurrence deceased due to lung cancer. On the other hand, two patients developed recurrence of HNC that was originally advanced. Recurrent tumors were surgically resected and both patients remain alive without recurrence. Salvage surgery was performed for $9(47 \%)$ of 19 patients with either remnant or recurrent HNCs, while the rate was only $14 \%(3 / 22)$ in patients with ESCC. The 3-year and 5-year overall survival rates after simultaneous CRT were $49 \%$ and $44 \%$ respectively (Figure $2 \mathrm{~B}$ ). 
Table II. Therapeutic effects of simultaneous definitive chemoradiotherapy to synchronous double cancers of esophagus and head and neck.

\begin{tabular}{|c|c|c|c|c|c|}
\hline \multirow{2}{*}{$\begin{array}{l}\text { TNM stage } \\
\text { (UICC Ver.7) }\end{array}$} & \multirow[b]{2}{*}{$\mathrm{n}$} & \multicolumn{2}{|c|}{ Responder $(\mathrm{CR}+\mathrm{PR})$} & \multicolumn{2}{|c|}{ CR } \\
\hline & & $\begin{array}{c}\text { No. of } \\
\text { cases }\end{array}$ & $(\%)$ & $\begin{array}{c}\text { No. of } \\
\text { cases }\end{array}$ & $(\%)$ \\
\hline \multicolumn{6}{|c|}{ Esophageal cancer } \\
\hline I & 27 & 23 & $(85)$ & 18 & (67) \\
\hline II & 3 & 3 & (100) & 2 & (67) \\
\hline III & 6 & 3 & $(50)$ & 0 & \\
\hline IV & 2 & 1 & $(50)$ & 0 & \\
\hline Total & 38 & & (79) & 22 & $(58)$ \\
\hline \multicolumn{6}{|l|}{$\begin{array}{l}\text { Head and neck } \\
\text { cancer }\end{array}$} \\
\hline I & 9 & 9 & (9) & 9 & $(100)$ \\
\hline II & 12 & 9 & (75) & 9 & (75) \\
\hline III & 5 & 5 & $(100)$ & 1 & (20) \\
\hline IV & 12 & 11 & $(92)$ & 0 & \\
\hline Total & 38 & 34 & (89) & 19 & $(50)$ \\
\hline
\end{tabular}

Simultaneous surgical resection. Table IV shows the procedures that were used in the simultaneous surgical resection of ESCC and HNC. The organs of HNC included the pharynx $(n=10)$, larynx in $(n=3)$, and the oral floor in $(n=3)$. Total pharyngo-laryngo-esophagectomy (PLE) was performed by a transthoracic approach in 9 patients. On the other hand, it was performed by a transhiatal approach in 3 patients with superficial ESCC. Oral floor resection and tonsillectomy were performed for oral cancer and oropharyngeal cancer, respectively. Pharyngolaryngectomy and cervical esophagectomy plus distal esophagectomy were performed in a patient with lower esophageal cancer with hypopharyngeal cancer. Regarding reconstruction, a gastric tube was used for 13 patients, which included 3 patients in which it was interposed by free jejunum since the length of the gastric tube was judged to be short. For one previously gastrectomized patient, a two-stage operation was performed since a single-stage operation was considered to be extremely invasive. In addition to total PLE, a free jejunal graft was also transferred, and the distal end of the transferred jejunum was placed into the neck as a jejunostomy during the first-stage operation. During the second stage, the distal end of the transferred jejunum was anastomosed to the elevated terminal ileum (Figure 3). Microvascular anastomoses were added in 8 patients in order to preserve the blood flow in the reconstructed conduits.

Postoperative complications developed in 3 patients (20\%), including anastomotic leakage in 2 patients and hypoxia in 1 patient. We had never experienced in-hospital death after simultaneous surgical resection. The 3- and 5year survival rates were both 67\% (Figure 2B).

\section{Discussion}

The association between ESCC and HNC is frequently recognized. In the current study, synchronous HNC was observed in $9.7 \%$ of the patients with ESCC. A nationwide registry of 5066 Japanese patients with esophageal cancer treated in 2004 showed that second cancers in another organ were present in 981 patients (19.4\%). Gastric cancer was the most common form of cancer (353 lesions), followed by $\mathrm{H} \& \mathrm{~N}$ cancer, including 162 pharyngeal cancers, 66 laryngeal cancers and 24 cancers in the oral cavity (17). We previously reported that both heavy smoking and heavy drinking are well-established risk factors for HNC and ESCC, and for multiple occurrences of cancer in these areas $(2,18,19)$; the current study revealed the synchronous combination of superficial ESCC and advanced HNC are most frequently recognized. Most ESCC lesions were detected by screening endoscopy, which was performed for the purpose of deciding the treatment strategy for advanced HNC. We have routinely performed endoscopy for HNC patients, while the head and neck regions have also been routinely examined in ESCC patients. These data support the significance of surveillance for synchronous double cancer.

Associated HNC is one of the most significant problems in determining the treatment strategy for ESCC. Multiple factors must be considered when determining the treatment strategy, especially when the treatment will involve surgery $(5,20)$. In such cases, the curability of both cancers must be carefully evaluated based on an accurate assessment of the tumor stage. If both tumors are potentially curable, each lesion should be treated individually, as though each were a single distinctive, primary lesion. On the other hand, we have to consider not only the invasiveness of the treatment on the basis of the patient's general status and comorbidities, but also their quality of life after treatment, including the vocal and swallowing functions. Based on these concepts, the appropriate therapies for these double cancers are determined and various combination treatments have been applied, as shown in Table I.

Simultaneous definitive CRT has been difficult due to the wide radiation field. We have aggressively adopted this treatment and have previously reported its efficacy and feasibility $(13,14)$. In this study, we further analyzed the clinical effects, including recurrence and prognosis in 38 patients. As a result, definitive radiotherapy was completed in $95 \%$ of the patients. One patient deceased due to aspiration pneumonia during the treatment; however, the treatment was tolerable in the other patients. CRT was more effective for patients with earlier cancers of the esophagus as well as the head and neck (Table II). However, the clinical results in $\mathrm{HN}$ seemed to be more favorable than those in ESCC. All of the lesions of stage I HNC showed a CR after treatment, while the response rate was $67 \%$, even in stage I esophageal cancer. 

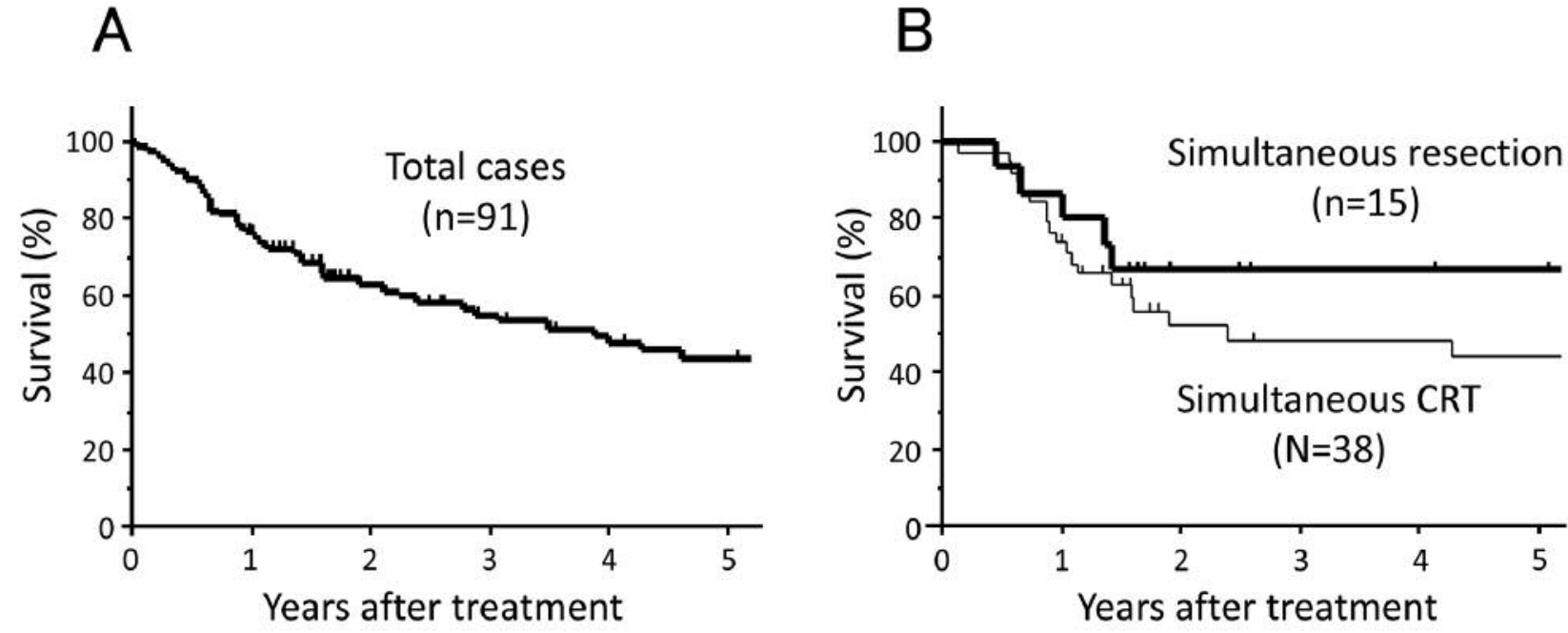

Figure 2. The overall survival after treatment. A. The overall survival curves in 91 patients with synchronous esophageal squamous cell carcinoma (ESCC) and head and neck cancer (HNC). B. The overall survival curves after simultaneous definitive chemoradiotherapy (CRT, thin line) and after simultaneous surgical resection (bold line).

Table III. Recurrence of the lesion which show complete response after definitive chemoradiotherapy (CRT) and its treatment.

\begin{tabular}{|c|c|c|c|c|c|}
\hline \multirow[t]{2}{*}{ Case } & \multirow{2}{*}{$\begin{array}{c}\text { Cancer developing recurrence } \\
\text { TNM stage }\end{array}$} & \multicolumn{3}{|c|}{ Details of recurrence } & \multirow{2}{*}{$\begin{array}{l}\text { Prognosis after } \\
\text { recurrence }\end{array}$} \\
\hline & & Site & $\begin{array}{l}\text { Time after initial } \\
\text { definitive CRT }\end{array}$ & Treatment & \\
\hline 1 & Esophageal cancer T1aN0M0, stage Ia & Mediastinal nodes & 8 months & CRT & Dead 9 months \\
\hline 2 & Esophageal cancer T1bN0M0, stage Ia & Thoracic esophagus & 29 months & RALS & Dead 29 months \\
\hline 3 & Esophageal cancer T1bN0M0, stage Ia & Thoracic esophagus & 27 months & Endoscopic resection & $\begin{array}{l}\text { Dead due to lung cancer } \\
38 \text { months }\end{array}$ \\
\hline 4 & Esophageal cancer T1bN0M0, stage Ia & Mediastinal nodes & 52 months & CRT & Dead 29 months \\
\hline 5 & Hypopharyngeal cancer T1N1M0, stage III & Cervical esophagus & 3 months & Total PLE* & Alive 58 months \\
\hline 6 & Laryngeal cancer T2NOM0, stage II & Larynx & 7 months & Laryngectomy & Alive 47 months \\
\hline
\end{tabular}

*PLE: Pharyngo-laryngo-esophagectomy.

Table IV. Operative procedure for simultaneous resections.

Operative procedures

\section{Resection}

Total pharyngo-laryngo-esophagectomy (trans-thoracic approach)

Total pharyngo-laryngo-esophagectomy

Resection of oral floor and esophagectomy

Tonsillectomy and esophagectomy

Pharyngo-laryngo-cervical esophagectomy plus Distal esophagectomy
Reconstruction

Gastric tube

Gastric tube with free jejunum interposition

Right hemi-colon with free jejunum interposition $\quad 1$

Gastric tube

1

(Trans-hiatal approach)

Gastric tube with free jejunum interposition

Gastric tube

Gastric tube

Free jejunal graft Roux-en Y 


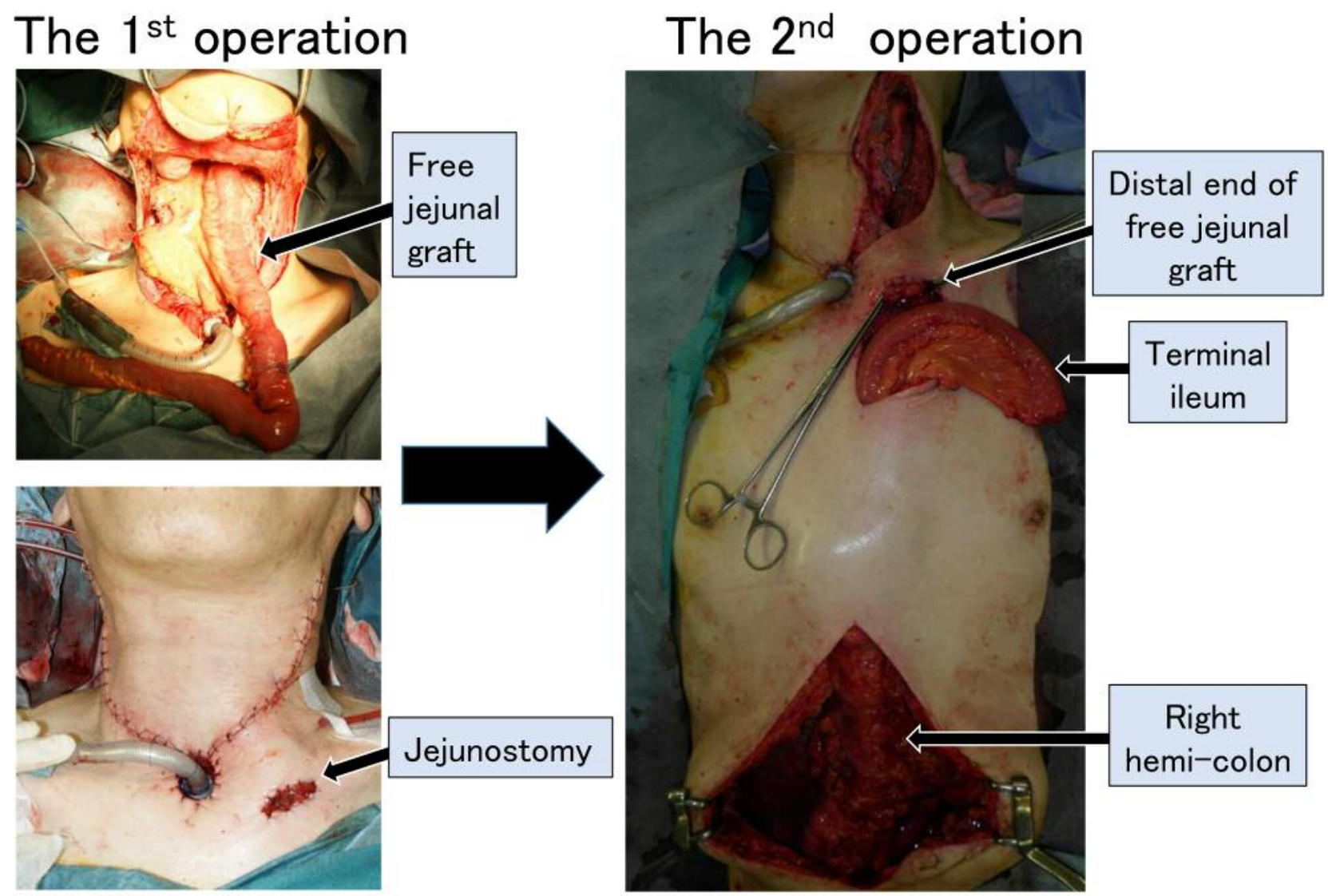

Figure 3. The surgical procedures in staged operations that consisted of total pharyngo-laryngo-esophagectomy plus free jejunal transfer during the first stage and reconstruction with right hemi-colon interposition three weeks later. This application makes it possible to avoid microvascular anastomosis during the second-stage operation, in which fibrous adhesion would develop. Furthermore, it results in the easier management of saliva outflow.

Recurrence after CR is frequently recognized, even in early ESCC and the clinical results of the therapy for recurrent disease were not favorable. Furthermore, salvage therapy for either remnant or recurrent disease after CRT was more frequently available for HN, in comparison to ESCC. Total PLE was performed for a patient with a local recurrence of hypopharyngeal cancer. The patient remains alive without recurrence. However, this operation as a salvage treatment is reported to be extremely high-risk, with high rates of mortality (22\%) and morbidity (44\%), and should be carefully planned and conducted in selected centers of excellence (4). Long-term survival after definitive CRT was achieved in $44 \%$ of patients. These results indicate that simultaneous definitive CRT for double cancer is a feasible and effective treatment; however, ESCC may be more resistant to this type of therapy in comparison to HNC.

Especially when surgical resection is adopted for synchronous ESCC and HNC, the surgical process, which includes the resection of both cancers and reconstruction, tends to be extremely invasive and complicated. Furthermore, it frequently results in a disturbance of the vocal and swallowing functions. We have aggressively indicated simultaneous surgical resection for such cases of double cancer, while adopting plastic surgery techniques, such as microvascular anastomosis and muscle flap, and staged operations $(5,6)$. Microvascular anastomosis is a useful technique for the resection of such double cancers. In such cases, the blood flow of the reconstructed conduits tends to be unstable and may result in serious necrosis. We have frequently adopted not only microvascular venous anastomosis (super-drainage) but also arterial anastomosis after total PLE, in order to stabilize the blood flow of the distal end of the reconstructed organ. Staged operations, that consist of an initial stage in which resection is performed and a secondary stage in which reconstruction is performed several weeks later, can reduce the surgical stress in high-risk operations. Staged operations were performed for high-risk patients with thoracic esophageal cancer (21). The original procedure was esophagectomy, cervical esophago- 
stomy and tube-jejunostomy; this was followed by reconstruction three weeks later (21). This staged operation was performed in cases of extremely invasive total pharyngolaryngo- esophagectomy by adopting pharyngostomy $(22,23)$. In the current case, we initially performed total PLE plus free jejunal transplantation, as previously reported (6). The proximal end of the jejunal graft was anastomosed to the pharynx and the distal end was used for the jejunostomy. Reconstruction with the right hemi-colon was performed secondarily. This approach makes it possible to avoid microvascular anastomosis during the second-stage operation, in which fibrous adhesion would develop. Furthermore, it results in the easier management of the saliva outflow.

The clinical outcomes, including mortality and morbidity, as well as prognosis after simultaneous resection were acceptable. These results indicate that simultaneous resection is an effective treatment option when appropriate techniques are applied for each case, such as staged operations and microvascular anastomosis, even in patients with double cancer of the esophagus and the head and neck.

The treatment strategy for synchronous ESCC and HNC must be decided after considering multiple factors, such as the stages of the respective tumors, the invasiveness of the therapies and the preservation of vital functions. Multiple combinations, based on the multidisciplinary therapy, are performed. Both simultaneous CRT and simultaneous resection are feasible and acceptable treatment options. Thus, the close cooperation of the medical staff, including surgeons from various fields and medical and radiological oncologists is essential.

\section{Funding}

This work was supported in part by a Grant-in-Aid from the Ministry of Education, Culture, Sport, Science and Technology of Japan and the Fujii Setsuro Memorial Foundation.

\section{Acknowledgements}

The Authors would like to thank Professor Brian Quinn for assisting with the preparation of the manuscript.

\section{References}

1 Morita M, Saeki H, Ito S, Kimura Y, Yamashita N, Ando K, Hiyoshi Y, Tokunaga E, Oki E, Ikeda T, Yoshida S, Nakashima $\mathrm{T}$ and Maehara Y: Surgical strategies for esophageal cancer associated with head and neck cancer. Surg Today 44: 16031610, 2014

2 Morita M, Kumashiro R, Kubo N, Nakashima Y, Yoshida R, Yoshinaga K, Saeki H, Emi Y, Kakeji Y, Sakaguchi Y, Toh Y and Maehara Y: Alcohol drinking, cigarette smoking, and the development of squamous cell carcinoma of the esophagus: epidemiology, clinical findings, and prevention. Int J Clin Oncol 15: 126-134, 2010
3 Morita M, Nakanoko T, Fujinaka Y, Kubo N, Yamashita N, Yoshinaga K, Saeki H, Emi Y, Kakeji Y, Shirabe K and Maehara Y: In-hospital mortality after a surgical resection for esophageal cancer: Analyses of the associated factors and historical changes. Ann Surg Oncol 18: 1757-1765, 2011.

4 Niwa Y, Koike M, Fujimoto Y, Oya H, Iwata N, Nishio N, Hiramatsu M, Kanda M, Kobayashi D, Tanaka C, Yamada S, Fujii T, Nakayama G, Sugimoto H, Nomoto S, Fujiwara M and Kodera Y: Salvage pharyngolaryngectomy with total esophagectomy following definitive chemoradiotherapy. Dis Esophagus 29: 598-602, 2016.

5 Morita M, Kawano H, Otsu H, Kimura Y, Saeki H, Ando K, Ida S, Oki E, Ikeda T, Kusumoto T, Fukushima J, Nakashima T and Maehara Y: Surgical resection for esophageal cancer synchronously or metachronously associated with head and neck cancer. Ann Surg Oncol 20: 2434-2439, 2013.

6 Morita M, Saeki H, Ito S, Ikeda K, Yamashita N, Ando K, Hiyoshi Y, Ida S, Tokunaga E, Uchiyama H, Oki E, Ikeda T, Yoshida S, Nakashima T and Maehara Y: Technical improvement of total pharyngo-laryngo-esophagectomy for esophageal cancer and head and neck cancer. Ann Surg Oncol 21: 1671-1677, 2014.

7 Matsumoto A, Watanabe M, Mine S, Nishida K, Shigaki H, Kawabata K, Yanaga K and Sano T: Comparison of synchronous versus staged surgeries for patients with synchronous double cancers of the esophagus and head-and-neck. Dis Esophagus 30: 1-6, 2017.

8 Cooper JS, Guo MD, Herskovic A, Macdonald JS, Martenson JA, Jr., Al-Sarraf M, Byhardt R, Russell AH, Beitler JJ, Spencer S, Asbell SO, Graham MV and Leichman LL: Chemoradiotherapy of locally advanced esophageal cancer: long-term follow-up of a prospective randomized trial (RTOG 85-01). Radiation Therapy Oncology Group. JAMA 281: 1623-1627, 1999.

9 Ordu AD, Nieder C, Geinitz H, Scherer V, Kup PG, Schuster T, Combs SE and Fakhrian K: Association between radiation dose and pathological complete response after preoperative radiochemotherapy in esophageal squamous cell cancer. Anticancer Res 34: 7255-7261, 2014.

10 Rades D, Seidl D, Wollenberg B, Schild SE and Hakim SG: Radiochemotherapy with Paclitaxel for Recurrent Previously Irradiated Squamous Cell Carcinoma of the Head and Neck. Anticancer Res 36: 5463-5468, 2016.

11 Yoshida R, Morita M, Ando K, Masuda T, Saeki H, Oki E, Sadanaga N, Nakashima T, Kakeji Y and Maehara Y: Salvage esophagectomy after definitive chemoradiotherapy for synchronous double cancers of the esophagus and head-andneck. Dis Esophagus 23: 59-63, 2010.

12 Wallach JB, Rosenstein MM and Kalnicki S: Localized synchronous squamous cell carcinomas of the esophagus and hypopharynx treated with definitive concurrent chemoradiotherapy with a unified radiotherapy plan. Curr Oncol 21: e354-357, 2014.

13 Shinoto M, Shioyama Y, Sasaki T, Nakamura K, Ohura H, Toh Y, Higaki Y, Yamaguchi T, Ohnishi K, Atsumi K, Hirata H and Honda $\mathrm{H}$ : Clinical results of definitive chemoradiotherapy for patients with synchronous head and neck squamous cell carcinoma and esophageal cancer. Am J Clin Oncol 34: 362-366, 2011.

14 Saeki H, Toh Y, Morita M, Sugiyama M, Morita K, Sakamoto Y, Soejima Y, Minami K, Sakaguchi Y, Hogaki Y, Uehara S, Okamura T, Maehara Y: The treatment outcomes of synchronous and metachronous esophageal squmous cell carcinoma and head and neck squamous cell carcinoma. Esophagus 9: 158-164, 2012. 
15 UICC. TNM Classification of Malignant tumors (7th edition). New York: Wiley, 2009.

16 Toh Y, Kitagawa Y, Kuwano H, Kusano M, Oyama T, Muto M, Kato H, Takeuchi H, Doki Y, Nemoto K, Matsubara H, Miyazaki T, Yanagisawa A and Uno T: A nation-wide survey of follow-up strategies for esophageal cancer patients after a curative esophagectomy or a complete response by definitive chemoradiotherapy in Japan. Esophagus 13: 173-181, 2016.

17 Ozawa S, Tachimori Y, Baba H, Fujishiro M, Matsubara H, Numasaki H, Oyama T, Shinoda M, Takeuchi H, Teshima T, Udagawa H, Uno T and Barron JT: Comprehensive registry of esophageal cancer in Japan, 2004. Esophagus 9: 75-98, 2012.

18 Morita M, Kuwano H, Ohno S, Sugimachi K, Seo Y, Tomoda H, Furusawa $\mathrm{M}$ and Nakashima T: Multiple occurrence of carcinoma in the upper aerodigestive tract associated with esophageal cancer: reference to smoking, drinking and family history. Int J Cancer 58: 207-210, 1994.

19 Morita M, Araki K, Saeki H, Sakaguchi Y, Baba H, Sugimachi K, Yano K, Sugio K and Yasumoto K: Risk factors for multicentric occurrence of carcinoma in the upper aerodigestive tract-analysis with a serial histologic evaluation of the whole resected-esophagus including carcinoma. J Surg Oncol 83: 216-221, 2003.

20 Tachimori Y, Watanabe H, Kato H, Ebihara S, Ono I, Nakatsuka $\mathrm{T}$ and Harii K: Treatment for synchronous and metachronous carcinomas of the head and neck and esophagus. J Surg Oncol 45: 43-45, 1990.
21 Morita M, Nakanoko T, Kubo N, Fujinaka Y, Ikeda K, Egashira A, Saeki H, Uchiyama H, Ohga T, Kakeji Y, Shirabe K, Ikeda T, Tsujitani S and Maehara Y:Two-stage operation for high-risk patients with thoracic esophageal cancer: an old operation revisited. Ann Surg Oncol 18: 2613-2621, 2011.

22 Yoshida R, Morita M, Kumashiro R, Ikeda K, Egashira A, Saeki H, Ohga T, Shiratsuchi H, Fukushima J, Nakashima T, Kakeji Y and Maehara Y: Staged operation for synchronous quintuple cancer in the oral cavity, hypopharynx, and esophagus. Esophagus 9: 228-233, 2012.

23 Hisamatsu Y, Morita M, Saeki H, Egashira A, Ohga T, Kakji Y, Fukushima J, Nakashima T and Maehara Y: Staged resection and reconstruction following definitive chemoradiotherapy for perforated cervico-thoracic esophageal cancer with mediastinal abscess. Esophagus 8: 197-201, 2011. 